\title{
Biochemical quantitation of the elF5A hypusination in Arabidopsis thaliana uncovers ABA-dependent regulation
}

\author{
1 Instituto de Biología Molecular y Celular de Plantas, CSIC-Universidad Politécnica de Valencia, Valencia, Spain \\ ${ }^{2}$ Centro de Investigación Príncipe Felipe, Valencia, Spain \\ ${ }^{3}$ Departamento de Química Orgánica, Universidad de Valencia, Valencia, Spain \\ ${ }^{4}$ Departament de Bioquímica i Biologia Molecular, Universitat Autònoma de Barcelona, Barcelona, Spain
}

Borja Belda-Palazón ${ }^{1}$, María A. Nohales ${ }^{1+}$, José L. Rambla ${ }^{1}$, José L. Aceña ${ }^{2+}$, Oscar Delgado ${ }^{2 \dagger}$, Santos Fustero ${ }^{2,3}$, M. Carmen Martínez ${ }^{4}$, Antonio Granell ${ }^{1}$, Juan Carbonell ${ }^{1}$ and Alejandro Ferrando ${ }^{1 *}$

\section{Edited by:}

Katja Baerenfaller, Swiss Federal Institute of Technology Zurich,

Switzerland

Reviewed by:

Torsten Kleffmann, University of

Otago, New Zealand

John S. Garavelli, University of

Delaware, USA

\section{*Correspondence:}

Alejandro Ferrando, Instituto de

Biología Molecular y Celular de

Plantas, CSIC-Universidad

Politécnica de Valencia, C/Ingeniero

Fausto Elio, s/n, 46022 Valencia,

Spain

e-mail: aferrando@ibmcp.upv.es

${ }^{\dagger}$ Present address:

María A. Nohales, Dana and David

Dornsife College of Letters Arts and

Sciences, University of Southern

California, Los Angeles, USA;

José L. Aceña, Departamento de

Química Orgánica, Universidad del

País Vasco, San Sebastián, Spain;

Oscar Delgado, Chemistry

Department, Jansen Research and

Development, Toledo, Spain
The eukaryotic translation elongation factor elF5A is the only protein known to contain the unusual amino acid hypusine which is essential for its biological activity. This post-translational modification is achieved by the sequential action of the enzymes deoxyhypusine synthase (DHS) and deoxyhypusine hydroxylase (DOHH). The crucial molecular function of elF5A during translation has been recently elucidated in yeast and it is expected to be fully conserved in every eukaryotic cell, however the functional description of this pathway in plants is still sparse. The genetic approaches with transgenic plants for either elF5A overexpression or antisense have revealed some activities related to the control of cell death processes but the molecular details remain to be characterized. One important aspect of fully understanding this pathway is the biochemical description of the hypusine modification system. Here we have used recombinant elF5A proteins either modified by hypusination or non-modified to establish a bi-dimensional electrophoresis (2D-E) profile for the three elF5A protein isoforms and their hypusinated or unmodified proteoforms present in Arabidopsis thaliana. The combined use of the recombinant 2D-E profile together with 2D-E/western blot analysis from whole plant extracts has provided a quantitative approach to measure the hypusination status of elF5A. We have used this information to demonstrate that treatment with the hormone abscisic acid produces an alteration of the hypusine modification system in Arabidopsis thaliana. Overall this study presents the first biochemical description of the post-translational modification of elF5A by hypusination which will be functionally relevant for future studies related to the characterization of this pathway in Arabidopsis thaliana.

Keywords: spermidine, hypusine, elF5A, 2D-electrophoresis, abscisic acid

\section{INTRODUCTION}

The eukaryotic cell contains polyamines, metabolites derived from amino acid catabolism that behave as polycations at physiological $\mathrm{pH}$. Among the most abundant natural polyamines, the triamine spermidine has been shown to be essential for cell viability (Hamasaki-Katagiri et al., 1997; Imai et al., 2004; Mandal et al., 2013). Genetic alterations of spermidine metabolism in S. cerevisiae have shown that one crucial function for spermidine to support growth is the modification of the translation elongation factor eIF5A (Chattopadhyay et al., 2008). In fact, the biological activity of eIF5A is dependent on spermidine by means of a well-characterized post-translational enzymatic modification named hypusination with the sequential intervention of two enzymes namely deoxyhypusine synthase (DHS) and deoxyhypusine hydroxylase (DOHH) (Park, 2006; Wolff et al., 2007). In the limiting first reaction, the enzyme DHS catalyzes the NADdependent cleavage and transfer of the aminobutyl moiety of the spermidine to the $\varepsilon$-amino group of one conserved lysine of eIF5A to form an intermediate residue named deoxyhypusine. In the second reaction that intermediate is hydroxylated by the $\mathrm{Fe}(\mathrm{II})$-dependent enzyme DOHH to yield the hypusine residue in the active and mature eIF5A proteoform. The activity of eIF5A itself is essential for cell survival in eukaryotes (Kang and Hershey, 1994; Park et al., 1997; Nishimura et al., 2002, 2012; Pagnussat et al., 2005; Feng et al., 2007). eIF5A has been postulated as an RNA-binding protein involved in mRNA transport and metabolism (Xu and Chen, 2001; Xu et al., 2004; Li et al., 2010; Maier et al., 2010). However, the best characterized cellular activity for eIF5A is its function as a translation factor involved in the elongation step (Gregio et al., 2009; Saini et al., 2009). Recent studies have elucidated a more detailed function within the ribosome for eIF5A and EF-P, a prokaryotic structural homolog. These proteins are required in their respective systems for the translation of mRNAs encoding clusters of consecutive proline residues that cause ribosome stalling (Doerfel et al., 2013; Gutierrez et al., 2013). The characterization of the eIF5A pathway in plants has focused on genetic approaches to overexpress or knock-down either the eIF5A genes or the modifying enzyme DHS. These studies have proposed functions for eIF5A related to either developmental or stress-induced cell death 
processes mostly characterized in A. thaliana whose genome carries three genes encoding very similar eIF5A proteins (Duguay et al., 2007; Feng et al., 2007; Liu et al., 2008; Ma et al., 2010; Xu et al., 2011; Wang et al., 2012; Ren et al., 2013). However, despite the availability of detailed functional genetic data, there is a lack of molecular evidence for eIF5A activity in plants. This may be in part due to the absence of biochemical tools to evaluate the eIF5A activity since the identity of the mRNAs regulated at the post-transcriptional level by eIF5A are unknown in plants.

One approach to understand eIF5A activity relies in its complex post-translational modifications as it has been reported that eIF5A can be subjected to phosphorylation, acetylation, ubiquitylation, and hypusination that regulate its stability, subcellular localization, and functional activity (Park et al., 1993; Jin et al., 2003; Lee et al., 2009; Łebska et al., 2010; Ishfaq et al., 2012). The hypusination of eIF5A yields a modified lysine residue with increased molecular weight and altered isoelectric point that can be used to biochemically distinguish both proteoforms (Klier et al., 1995). In this work we have generated recombinant versions of hypusinated and non-hypusinated eIF5A proteins from Arabidopsis thaliana that have been used to establish a biochemical profile of the different eIF5A proteins and their proteoforms by means of 2D-E and western blot analysis. We have also applied this biochemical technique to show that the plant stress hormone abscisic acid causes a reduction in the hypusination of eIF5A1 probably through the post-transcriptional alteration of DHS activity.

\section{MATERIALS AND METHODS PLANT MATERIAL AND GROWTH CONDITIONS}

Arabidopsis wild type (Col-0) and $C K A 3^{m u t}$ plants were grown in vitro with solid MS medium containing $2.45 \mathrm{~g} / \mathrm{L}$ MS salts (Duchefa, The Netherlands) and $6 \mathrm{mM}$ MES buffer adjusting $\mathrm{pH} 5.7$ with $\mathrm{KOH}$ and solidified with $1 \%$ Phyto Agar. When needed, ABA plant hormone (Sigma, USA) or dexamethasone (Sigma, USA) was added as indicated. Arabidopsis seeds were surface sterilized by mixing around 100 seeds with $300 \mu \mathrm{L}$ of $70 \%$ ethanol and $0.05 \%$ Triton X-100 for 5 min while shaking. After centrifugation and supernatant removal, the seeds were incubated for $5 \mathrm{~min}$ shaking with the same volume of $96 \%$ ethanol and sown by pipetting on sterile filter paper under laminar flow for $15 \mathrm{~min}$ for ethanol evaporation. Once dried the seeds were sawn on MS medium in Petri dishes sealed with Micropore (3M, USA) and stratified for 3 days at $4^{\circ} \mathrm{C}$ before being cultivated in growth chamber under long day photoperiod conditions $(16 \mathrm{~h}$ light intensity $110 \mu \mathrm{mol} \mathrm{m} \mathrm{m}^{-2} \mathrm{~s}^{-1}$ and $8 \mathrm{~h}$ dark) at $22^{\circ} \mathrm{C} \pm 1^{\circ} \mathrm{C}$.

\section{CLONING PROCEDURES}

The cloning procedures for heterologous expression in E. coli as translational fusions to either His or GST-tags were carried out following a two-step sequential PCR as previously described (Belda-Palazón et al., 2012). Gene coding sequences of eIF5A1, eIF5A2, eIF5A3, DHS, and DOHH were PCR-amplified from A. thaliana cDNA using the following primers for eIF5A1: 5' - GG ACA AGT TTG TAC AAA AAA GCA GGC TTA ATG TCC GAC GAG GAG CAT CAC- $3^{\prime}$ and $5^{\prime}$ - GG AC CAC TTT GTA CAA GAA AGC TGG GTC CTT GGG ACC GAT GTC CTT AAG- 3’; for eIF5A2: 5' - GG ACA AGT TTG TAC AAA AAA GCA GGC TTA ATG TCT GAC GAC GAG CAC CAC- $3^{\prime}$ and $5^{\prime}-\mathrm{GG}$ AC CAC TTT GTA CAA GAA AGC TGG GTC CTT GCC ACC ACC AAC TTC CTT- 3' ; for eIF5A3: 5' - GG ACA AGT TTG TAC AAA AAA GCA GGC TTA ATG TCA GAC GAC GAG CAT CAC$3^{\prime}$ and $5^{\prime}-$ GG AC CAC TTT GTA CAA GAA AGC TGG GTC CTT GGG ACC AAC TTC CTT GAG- 3'; for DHS: 5' - GG ACA AGT TTG TAC AAA AAA GCA GGC TTA ATG GAG GAT GAT CGT GTT TTC- $3^{\prime}$ and 5'- GG AC CAC TTT GTA CAA GAA AGC TGG GTC AGT CTT AGA CTC ACA GGT TTG- 3'; for DOHH: 5' - GG ACA AGT TTG TAC AAA AAA GCA GGC TTA ATG GAA TCT AAT GGA TCA GTT $-3^{\prime}$ and $5^{\prime}-$ GG AC CAC TTT GTA CAA GAA AGC TGG GTC GTG AAC AAG CGG GTC TTG CGT $-3^{\prime}$ and the PCR products were used to obtain the entry clones in pDONR-Zeo (Invitrogen, USA). The entry clones were subcloned into pDEST15 (Invitrogen, USA) for heterologous GST fusion protein expression without post-translational modifications. To obtain the recombinant eIF5A hypusinated proteins, the entry clones containing eIF5A genes were subcloned into pQlinkGD (Addgene plasmid \#13673) to obtain GST fusion proteins, whereas both entry clones with the modification enzymes DHS and DOHH were subcloned into pQlinkHD (Addgene plasmid \#13668) to yield His-tag enzymes. pQlink vectors provided by Addgene were a gift of Kondrad Buessow and all ligation-independent cloning methods were followed as reported (Scheich et al., 2007). In a first step DOHH-His was subcloned as a PacI restriction fragment into SwaI-digested pQlinkHD-DHS to obtain His-DHS/His-DOHH double construct. Subsequently this double construct linearized with SwaI was used for the subcloning of PacI restriction fragments of each GST-eIF5A construct to yield the three final constructs DHS/DOHH/eIF5A1pQlink, DHS/DOHH/eIF5A2-pQlink, and DHS/DOHH/eIF5A3pQlink. Each final construct was introduced into E. coli strain BL21-CodonPlus (DE3) (Stratagene-Agilent, USA) for recombinant heterologous protein expression. Nucleic acid handling and plasmid images were performed with software VectorNTI Suite 9 (Invitrogen, USA).

\section{RECOMBINANT PROTEIN PURIFICATION AND PLANT PROTEIN EXTRACTION}

Bacterial growth conditions and isopropyl- $\beta$-Dthiogalactopyranoside (IPTG) induction were performed as described (Belda-Palazón et al., 2012). Collected cells were resuspended with $0.5 \mathrm{~mL}$ extraction buffer containing $20 \mathrm{mM}$ Tris- $\mathrm{HCl} \mathrm{pH}$ 7.6, $150 \mathrm{mM} \mathrm{NaCl}, 1 \mathrm{mM}$ DTT and protease inhibitor cocktail (Sigma, USA), sonicated, and centrifuged for $15 \mathrm{~min}$ to remove cell debris and insoluble material. To purify GST-tag proteins, total soluble proteins were loaded on a $1 \mathrm{~mL}$ Glutathione agarose resin (ABT, Spain) and incubated overnight at $4^{\circ} \mathrm{C}$. After exhaustive washing, the resin-bound GST-tag proteins were eluted twice by incubation at $4^{\circ} \mathrm{C}$ for $5 \mathrm{~min}$ with $1 \mathrm{~mL}$ elution buffer containing $50 \mathrm{mM}$ Tris- $\mathrm{HCl} \mathrm{pH} 8.0$ and $10 \mathrm{mM}$ L-glutathione. To remove excess glutathione and concentrate the protein, the samples were washed with TBS buffer $(20 \mathrm{mM}$ Tris- $\mathrm{HCl}$ and $150 \mathrm{mM} \mathrm{NaCl})$ through Vivaspin $5 \mathrm{kDa}$ MWCO (GE Healthcare, USA) according to the manufacturer instructions. To cleave the GST tag, the GST-eIF5A purified 
proteins were bound again to the Glutathione agarose beads and, after washing with $20 \mathrm{mM}$ Tris- $\mathrm{HCl}, 150 \mathrm{mM} \mathrm{NaCl}, 1 \mathrm{mM}$ DTT, and $1 \mathrm{mM}$ EDTA, cleavage of the GST was achieved by overnight treatment at $4^{\circ} \mathrm{C}$ with Protease $3 \mathrm{C}$ PreScission protease (GE Healthcare, USA) according to the manufacturer. After collecting the soluble released eIF5A proteins, the remaining bound GST and Protease $3 \mathrm{C}$ were eluted by incubation with elution buffer.

For plant protein extraction, plant seedlings were ground in lysis buffer containing $50 \mathrm{mM}$ Tris- $\mathrm{HCl} \mathrm{pH} \mathrm{7.6,10 \%} \mathrm{glycerol,}$ $1 \mathrm{mM}$ DTT, $1 \mathrm{mM}$ EDTA, and 0.5\% Igepal containing plant protease inhibitor cocktail (Sigma, USA). The extract was centrifuged at least twice at $3000 \mathrm{~g}$ for $10 \mathrm{~min}$ at $4^{\circ} \mathrm{C}$ to remove cell debris and if needed filtered through $0.45 \mu \mathrm{m}$ polypropylene filter (VWR, USA). Total soluble proteins were precipitated by mixing for $1 \mathrm{~h}$ at $4^{\circ} \mathrm{C}$ with an equal amount of cold $20 \%$ TCA (trichloroacetic acid, Sigma). After centrifugation at $10,000 \mathrm{~g}$ for $15 \mathrm{~min}$, pellets were washed three times with cold acetone and finally resuspended by vortex and sonication in 2D-lysis buffer containing $7 \mathrm{M}$ urea, $2 \mathrm{M}$ thiourea, and 4\% CHAPS. Non-protein contaminants were removed using the $2 \mathrm{D}$ Clean-Up Kit according to the manufacturer (GE Healthcare, USA) and resolubilized in the 2Dlysis buffer for determination of protein concentration with the Bio-Rad (USA) protein assay.

\section{PROTEIN FLUORESCENT LABELING AND 2D ELECTROPHORESIS}

Recombinant hypusinated and non-hypusinated eIF5A proteins were labeled using the CyDyes DIGE fluors (Cy2, Cy3, and Cy5) according to the manufacturer (GE Healthcare, USA). Equal amounts $(1 \mu \mathrm{g})$ of each fluorescently labeled protein were pooled and 2D-lysis buffer was added to a final volume of $40 \mu \mathrm{L}$. The samples were then mixed with $40 \mu \mathrm{L}$ of isoelectrofocusing (IEF) rehydration buffer ( $8 \mathrm{M}$ urea, 4\% CHAPS, 0.005\% bromophenol blue) containing $65 \mathrm{mM}$ DTT and 1\% IPG buffer pH 3-11. For 2D-E analysis, strips of $7 \mathrm{~cm}$ in length with immobilized 4-7 $\mathrm{pH}$ gradient were hydrated overnight at room temperature with $125 \mu \mathrm{L}$ of IEF buffer containing the reagents Destreak and Pharmalyte according to the manufacturer (GE Healthcare, USA). Protein samples ( $15 \mu \mathrm{g}$ of total plant protein or $1 \mu \mathrm{g}$ fluorescently labeled recombinant protein) were loaded in hydrated strips. IEF was performed on an IPGphor unit (GE Healthcare, USA) at $20^{\circ} \mathrm{C}$ and a maximum current setting of $75 \mu \mathrm{A}$ per strip, using the following settings: $300 \mathrm{~V}$ for $45 \mathrm{~min}$, an increasing voltage gradient to $1000 \mathrm{~V}$ over $25 \mathrm{~min}$, an increasing voltage gradient to $5000 \mathrm{~V}$ over $2 \mathrm{~h}$, before finally holding at $5000 \mathrm{~V}$ for a total of $7000 \mathrm{Vh}$. After IEF, each strip was equilibrated separately for $15 \mathrm{~min}$ in $10 \mathrm{~mL}$ equilibration solution I $(0.05 \mathrm{M}$ Tris- $\mathrm{HCl}$ buffer, $\mathrm{pH} 8.8$ containing $6 \mathrm{M}$ urea, $30 \%$ glycerol, $2 \%$ SDS, $200 \mathrm{mg}$ DTT per $10 \mathrm{~mL}$ buffer) followed by equilibration solution II (substituting DTT for $250 \mathrm{mg}$ iodoacetamide per $10 \mathrm{~mL}$ buffer and adding $0.01 \%$ bromophenol blue) before being applied directly to the second dimension 14\% SDS-PAGE gels. After SDS-PAGE, gels were either coomassie-stained or used for immunoblot analysis. CyDye-labeled proteins were visualized by scanning using a Typhoon Trio scanner (GE Healthcare, USA) with the relevant wavelengths for each CyDye. Cy2 image were scanned using a blue laser $(488 \mathrm{~nm})$ and an emission filter of $520 \mathrm{~nm}$ band pass (BP) 40. Cy3 image were scanned using a
Table 1 | Primers for real-time qPCR.

\begin{tabular}{ll}
\hline Primer & Sequence \\
\hline DHS-F & CTCACAGGTTTGGTCTCTCTTTG \\
DHS-R & GTTCTGCTAAAACCGTTAAGGTATAC \\
elF5A1-F & GGAGAGGAACAGATCAATGCTC \\
elF5A1-R & GAGTAATGGAAGCCTACAGAAGAAG \\
elF5A2-F & TGCTCACTTCTCTCTCTTAGG \\
elF5A2-R & GATTCGCTGGCCTCAAAG \\
elF5A3-F & AGGATATTGTTGTGTCTGTCATG \\
elF5A3-R & TTATTATTATTACTTGGGACCAACTTC
\end{tabular}

green laser $(532 \mathrm{~nm})$ and a $580 \mathrm{~nm} \mathrm{BP} 30$ emission filter. Cy5 image were scanned using a red laser $(633 \mathrm{~nm})$ and a $670 \mathrm{~nm} \mathrm{BP}$ 30 emission filter. All gels were scanned at $200 \mu \mathrm{m}$ (pixel size) resolution. The photomultiplier tube (PMT) was set between 500 and $600 \mathrm{~V}$ by using normal sensitivity. The scanned gels were directly transferred to the ImageQuant V5.2 software package (GE Healthcare, USA).

\section{ANTIBODY PRODUCTION, IMMUNOLOGICAL METHODS, AND QUANTITATIVE RT-PCR}

To raise polyclonal antibodies against eIF5A1 protein, $2.5 \mathrm{mg}$ of the non-modified recombinant purified protein without GST tag were sent to BioGenes GmbH (Germany). The polyclonal antiserum produced by the company was tested at different dilutions in western blots to be optimally used at 1:5000. The same 1:5000 working dilution was used with secondary anti-rabbit antibody coupled to peroxidase (Santa Cruz Biotechnology, USA). Immunoblot detection was done with the chemiluminescent ECL detection kit (GE Healthcare, USA). For quantitative gene expression studies based on reverse transcriptase and quantitative PCR (RTqPCR) were performed as described (Cuevas et al., 2008). Primers used for qPCR are shown in Table 1 for the genes DHS, eIF5A1, eIF5A2, and eIF5A3. Primers for the reference gene PDF2 and the ABA-inducible genes $R A B 18$ and $R D 29 B$ were previously published (Czechowski et al., 2005; Saez et al., 2006; Cuevas et al., 2008).

\section{MALDI-TOF AND GC-MS}

$1.5 \mu \mathrm{g}$ of recombinant hypusinated and non-hypusinated eIF5A proteins were digested with sequencing grade trypsin (Promega, USA) as described (Shevchenko et al., 1996). For the MALDI TOFTOF analysis, $1 \mu \mathrm{L}$ of the digestion mixture was spotted onto the MALDI target plate. After the droplets were airdried at room temperature, $1 \mu \mathrm{L}$ of matrix containing $5 \mathrm{mg} / \mathrm{mL}$ CHCA ( $\alpha$-cyano-4-hydroxycinnamic acid, Bruker, USA) in $0.1 \%$ TFA (trifluoroacetic acid)-ACN (acetonitrile) $/ \mathrm{H}_{2} \mathrm{O}(1: 1 \mathrm{v} / \mathrm{v}$ ) was added and allowed to air-dry at room temperature. The resulting mixtures were analyzed in a 5800 MALDI TOFTOF (ABSciex, USA) in positive reflection mode (3000 shots every position). Previously the plate and the acquisition methods were calibrated with $0.5 \mu \mathrm{L}$ of the calibration mixture (ABSciex, USA) in 13 positions. The MS information was sent to MASCOT via the Protein Pilot (ABSciex, USA) and was analyzed manually with mMass v5.2.0 (Strohalm et al., 2008). The MALDI 
TOFTOF analysis was carried out in the SCSIE Proteomics laboratory of the Universidad de Valencia, a member of ISCIII Carlos III Network Proteomics Platform. The mass spectrometry proteomics data have been deposited to the ProteomeXchange Consortium (http://www.proteomexchange.org) via the PRIDE partner repository (Vizcaíno et al., 2013) with the dataset identifier PXD000880 and DOI 10.6019/PXD000880.

For the GC-MS studies, $0.4 \mathrm{mg}$ of purified recombinant GSTeIF5A2 protein, hypusinated or non-hypusinated, were eluted in TBS buffer. 1 volume of $37 \% \mathrm{HCl}$ was added and the solution was flame sealed in a glass vial, agitated, and incubated at $110^{\circ} \mathrm{C}$ for $24 \mathrm{~h}$ for complete acid hydrolysis. The resulting amino acid solution was dried in a speed-vacuum overnight, and derivatized by trimethylsilylation with MSTFA in pyridine as described (Zanor et al., 2009). Two microliters of the trimethylsilylated hydrolyzed protein were injected in splitless mode in a $6890 \mathrm{~N}$ gas chromatograph fitted with a secondary oven and a cryogenic modulator (Agilent Technologies, USA) coupled to a Pegasus 4D TOF mass spectrometer (LECO, USA). The 2D separation was achieved using a RTX-5 $(10 \mathrm{~m} \times 0.18 \mathrm{~mm} \times 0.20 \mu \mathrm{m})$ (Restek, USA) 1st-dimension column in the primary oven and a DB-17 $(1.1 \mathrm{~m} \times 0.10 \mathrm{~mm} \times 0.10 \mu \mathrm{m}) 2$ nd-dimension column in the secondary oven. The liner was set at $270^{\circ} \mathrm{C}$. Helium was used as carrier gas with a constant flow of $1 \mathrm{~mL} \mathrm{~min}{ }^{-1}$. Primary oven program was $70^{\circ} \mathrm{C}$ for $2 \mathrm{~min}, 20^{\circ} \mathrm{C} \mathrm{min}^{-1}$ ramp until $260^{\circ} \mathrm{C}$, and $260^{\circ} \mathrm{C}$ for $5 \mathrm{~min}$. Secondary oven temperature was programmed to maintain a temperature $20^{\circ} \mathrm{C}$ higher than the primary oven during all the run. Mass spectra were collected at 100 scans s$^{-1}$ in the $\mathrm{m} / \mathrm{z}$ range $60-800$. Ion source was set at $200^{\circ} \mathrm{C}$ and ionization energy at $70 \mathrm{eV}$. Identification of trimethylsilylated hypusine, deoxyhypusine, and other amino acids was based on comparison of both mass spectrum and retention index with those of pure standards. Hypusine and deoxyhypusine standards were chemically synthesized according to previously reported procedures (Bergeron et al., 1998).

\section{RESULTS \\ RECOMBINANT EXPRESSION AND BIOCHEMICAL SEPARATION OF HYPUSINATED AND NON-HYPUSINATED EIF5A PROTEINS FROM \\ A. THALIANA}

To evaluate differences in the 2D-E mobility of the three A. thaliana eIF5A proteins we cloned and expressed the corresponding cDNAs in E. coli, which does not contain any homologous proteins nor the hypusination enzymes DHS and deoxyhpusine hydroxylase (DOHH). The three cDNAs encoding eIF5A proteins were cloned and expressed as gluthathione-S-transferase (GST) fusion proteins including the Protease 3C-Prescission target sequence for cleavage of the GST tag that can be used to release the soluble eIF5A full length proteins (Figure 1A). All three recombinant proteins eIF5A1, eIF5A2, and eIF5A3 were labeled as full length proteins with different fluorescent dyes to follow their position after 2D-E. After mixing all three recombinant labeled proteins they were subjected to 2D-E and either coomassie staining or fluorescent scanning to distinguish the relative mobility of each protein. As shown in Figure 1B, and as expected from the theoretical isoelectric points, the eIF5A1 protein (pI 5.532) is more acidic than the eIF5A2 (pI 5.813) and

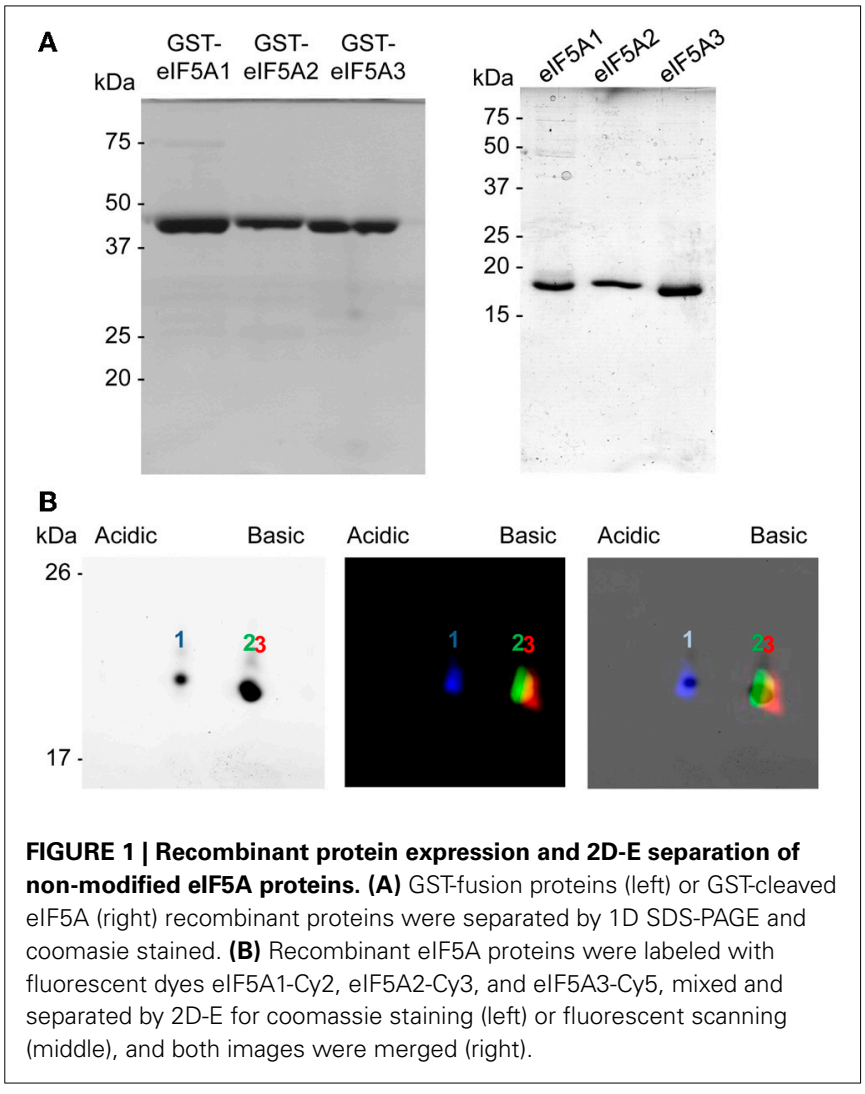

eIF5A3 (pI 5.816) proteins that display a very close pI with a slightly less acidic value for the eIF5A3 protein. These data indicate that the 2D-E technique can effectively separate eIF5A1 protein from eIF5A2 and eIF5A3 at least in their non-hypusinated proteoforms.

One remaining question was related to the apparent $2 \mathrm{D}-\mathrm{E}$ mobility of the hypusinated proteins. The successful production of active recombinant eIF5A in E. coli by coexpression with the modification enzymes has been reported (Park et al., 2011), accordingly we pursued the simultaneous coexpression of eIF5A proteins with the hypusination enzymes DHS and DOHH by cloning the corresponding cDNAs into the pQLink vectors that make use of the ligation-independent cloning technique (Scheich et al., 2007). Figure 2A shows a schematic picture of the multiple cloning construct and Figure $\mathbf{2 B}$ displays the purification of recombinant GST-eIF5A2 co-expressed together with the tagged hypusination enzymes His-DHS and His-DOHH. Similar experiments were done for GST-eIF5A1 and GST-eIF5A3 and finally all three GST-fusion proteins were cleaved by treatment with Protease $3 \mathrm{C}$ to release the soluble eIF5A proteins as shown in Figure 2C. To evaluate whether the eIF5A proteins were indeed hypusinated, two different approaches were followed. First we took advantage of the total conservation of the primary sequence of the tryptic peptide that includes the hypusinated $\mathrm{K}$ among distinct eukaryotic cells (TGK ${ }^{\text {Hyp }}$ HGHAK) that has been previously shown to resist trypsin cleavage when the otherwise susceptible $\mathrm{K}$ is modified by hypusination (Jin et al., 2003). We anticipated the presence of a tryptic peptide of $\mathrm{m} / \mathrm{z} 922.5$ if hypusination 


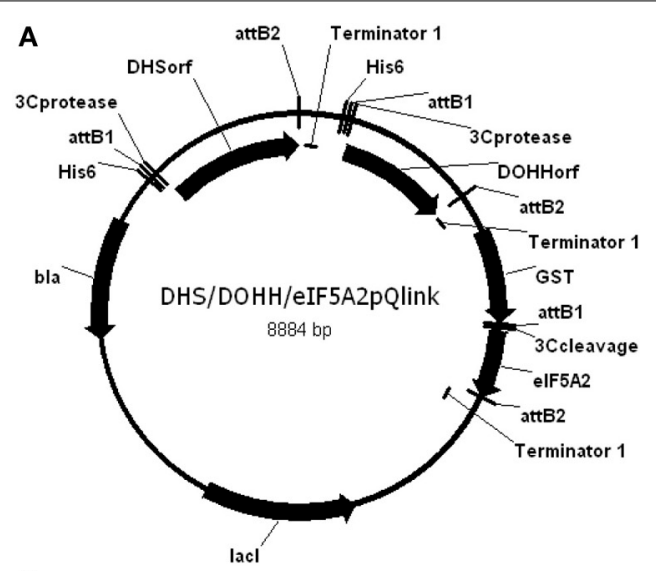

B

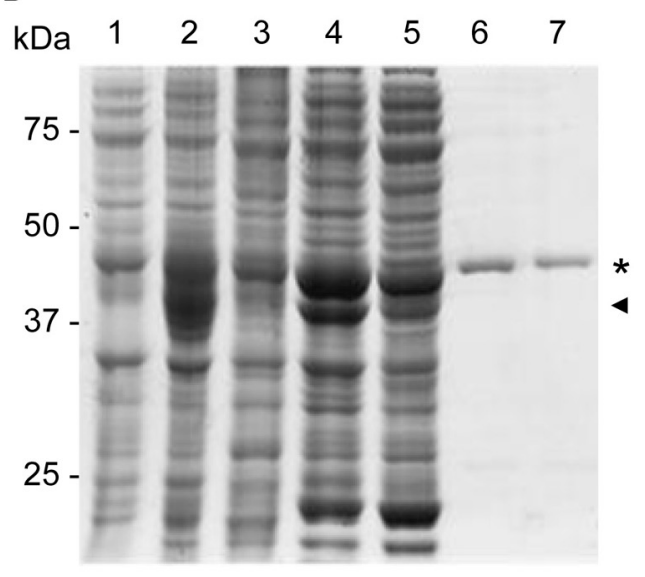

C

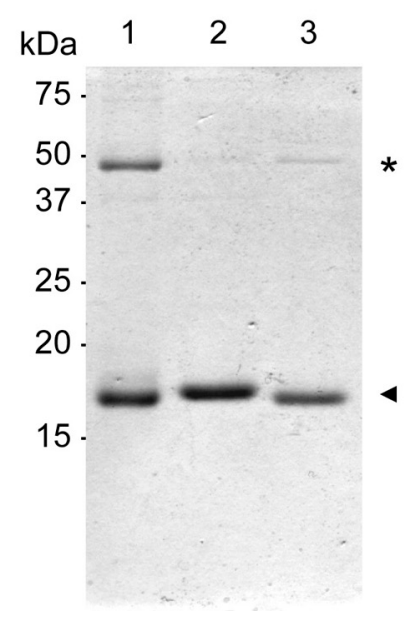

FIGURE 2 | Coexpression of GST-elF5A proteins and hypusination enzymes. (A) Schematic diagram of the resulting plasmid after LIC cloning into pQlink of GST-elF5A2 together with His-DHS and His-DOHH. (B) SDS-PAGE analysis of protein fractions for purification of hypusinated GST-elF5A2. The coomassie staining SDS-PAGE contains in lane 1 a total non-induced protein extract, lane 2 IPTG-induced total protein extract, lane 3 non-induced total soluble protein extract, lane 4 IPTG-induced soluble protein extract, lane 5 unbound protein extract to glutathione sepharose, lanes 6 and 7 soluble protein extract after elution by glutathione competition. Asterisk indicates the presence of GST-elF5A2 (45 kDa) partially overlapping with His-DHS (44 kDa), and arrowhead corresponds to

(Continued)

\section{FIGURE 2 | Continued}

His-DOHH (37 kDa). (C) Partially hypusinated GST-elF5A proteins immobilized on glutathione sepharose were cleaved with Protease $3 C$ and the resulting soluble fractions were separated on SDS-PAGE and coomassie stained to show the purification of elF5A1 (lane 1), elF5A2 (lane 2) and elF5A3 (lane 3) as indicated with arrowheads. Residual GST-eIF5A proteins are still present in the preparations as indicated with asterisks.

had occurred in the recombinant expressed eIF5A proteins. Both eIF5A proteins coexpressed with enzymes or not, were subjected to trypsin digestion and subsequent MALDI-TOF-MS analysis for the identification of the hypusinated tryptic peptide. As shown in Figure 3, one peptide of $\mathrm{m} / \mathrm{z} 922.5$ was identified only in the protein samples from the eIF5A proteins coexpressed with the hypusination enzymes and absent in the analysis when they were not. To further confirm that hypusine was present in those eIF5A proteins, an additional amino acid analysis was carried out with coexpressed GST-eIF5A3 fusion protein vs. GST-eIF5A3 that was not coexpressed. The analysis was performed by means of total amino acid hydrolysis and GCxGC-TOF-MS using chemically synthesized hypusine as a standard. As it is shown in Figure S1 only the coexpressed GST-eIF5A3 recombinant protein showed the presence of hypusine, thus confirming that the recombinant coexpressed proteins do contain the amino acid hypusine.

Once the presence of hypusine in the eIF5A proteins coexpressed with enzymes was confirmed, a differential fluorescent labeling was done for each of the three eIF5A proteins coexpressed or not, and subjected to 2D-E and either coomassie stained or fluorescent scanning. The results, shown in Figure 4 showed that all three coexpressed eIF5A proteins displayed two spots with different $\mathrm{pI}$. When compared with the mobility of the non-coexpressed recombinant proteins, a perfect overlap was found between the unmodified IF5A and the acidic spot of the hypusinated protein, thus suggesting that the less acidic spot should correspond to the hypusinated version of the eIF5A protein. This was confirmed in a second MALDI-TOF-MS test by picking and trypsin-digestion of the coomassie stained spots (more acidic and less acidic) from the hypusine-modified eIF5A2 gel showing identical results as those shown in Figure 3B. These 2D-E data also confirmed that the hypusinated eIF5A proteins were not completely modified, since a relevant percentage of the protein corresponded to the more acidic unmodified spot. This is the case for all three eIF5A proteins with variable amounts of hypusination ranging between 20 and $45 \%$. We tested alternative protocols for bacterial growth conditions changing both the media content and temperature, but no relevant improvements on the percentage of hypusination were achieved (data not shown). In spite of the partial modification of the recombinant eIF5A proteins, these proteins could be used to place the position of each eIF5A protein in their unmodified (more acidic spot) or hypusine-modified (less acidic spot) versions from a total protein extract from $A$. thaliana subjected to 2D-E analysis.

\section{CHARACTERIZATION OF THE PROTEOMIC PROFILE OF A. THALIANA EIF5A BY 2D-E AND WESTERN BLOT}

To develop a 2D-E based test from a plant protein extract, we needed first to raise antibodies against the eIF5A proteins. 

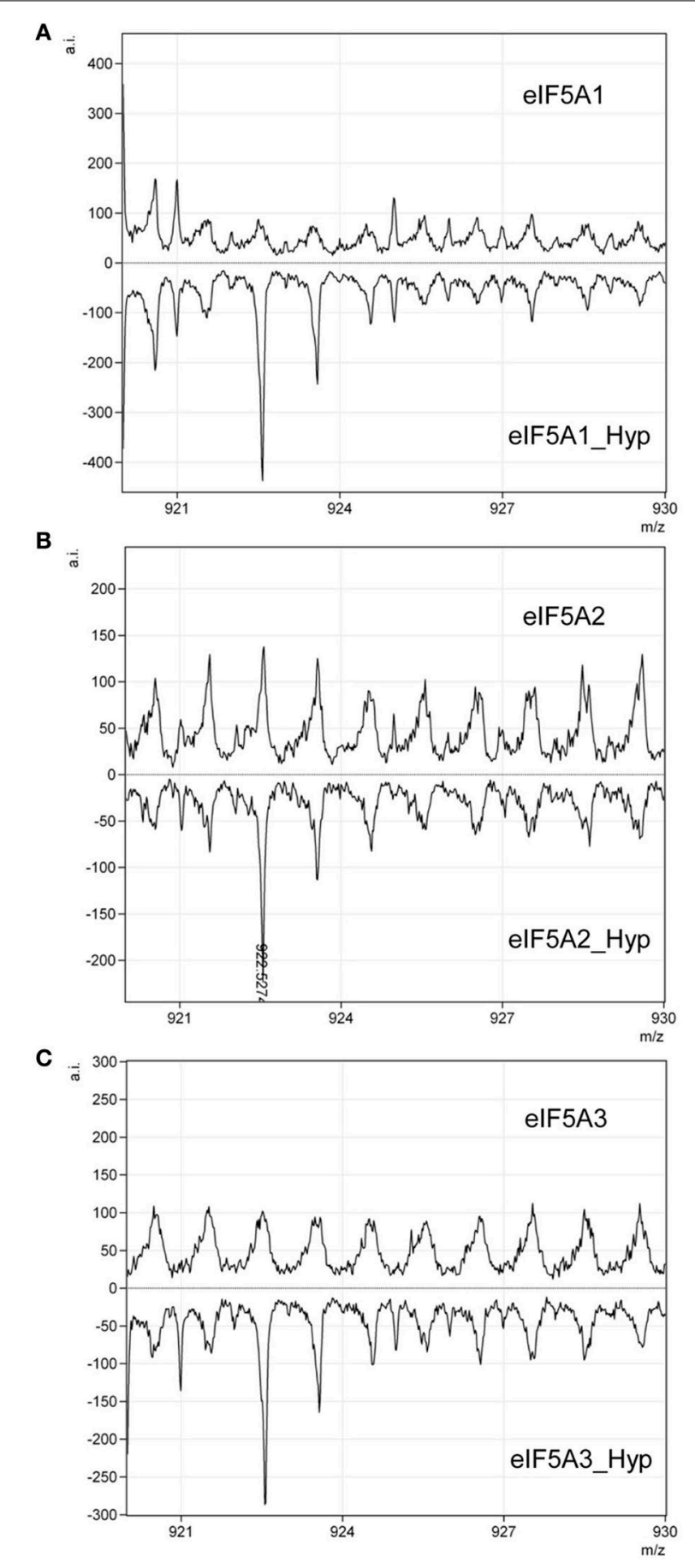

FIGURE 3 | Qualitative assessment of elF5A hypusination by MALDI-TOF. Recombinant elF5A proteins modified by hypusination or unmodified: elF5A1 (A), elF5A2 (B), and elF5A3 (C), were subjected to trypsin digestion and checked by MALDI-TOF for the presence or absence of a tryptic peptide of $\mathrm{m} / \mathrm{z}$ 922.5. Only hypusine-modified proteins showed the presence of the peptide of the expected $\mathrm{m} / \mathrm{z}$ as indicated in (B).

With this purpose we performed a large scale purification of recombinant eIF5A1 protein as shown in Figure 5A. The GSTeIF5A1 purified fusion protein was cleaved with Protease $3 \mathrm{C}$ to yield highly pure eIF5A1 protein that was used to raise polyclonal antibodies. In a western blot analysis against recombinant unmodified eIF5A proteins, the antibody was shown to recognize optimally the eIF5A1 protein but also to partially crossreact against eIF5A3 and to a minor extent also with eIF5A2 (Figure 5A). When testing by western blot diluted amounts of the recombinant proteins, differences in the detection limit were observed. Figure 5A shows an enhanced detection level for eIF5A1 compared to eIF5A2 or eIF5A3 proteins whose signals are neglectable in the low nanogram range. In a western blot analysis with total protein extract from $A$. thaliana seedlings, a single band of the expected size for eIF5A1 was immunodecorated showing the specificity of the antibody in a plant total protein extract. Taking into account the very similar MW for all three eIF5A proteins in A. thaliana, it seems impossible to differentiate each other or their post-translational modifications from experiments based on western blot of SDS-PAGE separated proteins.

Next we tested the immunodecoration profile of a total protein extract from A. thaliana seedlings separated by $2 \mathrm{D}-\mathrm{E}$ and compared the western blot signals with the mobility of the recombinant hypusinated eIF5A proteins fluorescently labeled. The results shown in Figure 5B allowed matching the western blot signals to the mobility of the fluorescent labeled recombinant proteins. One major signal from the western blot seems to decorate the co-migration of both eIF5A1 hypusinated protein together with eIF5A2 and eIF5A3 unmodified proteins. However, the immunoblot signal after 2D-E seems to be specific for eIF5A1, taking into account that the low amount of total protein used does not allow to reveal the presence of any eIF5A protein after silver staining, whose lowest detection threshold is in the low nanogram or subnanogram range (Chevallet et al., 2006). Although the endogenous gene expression level is higher for eIF5A2 and eIF5A3 genes than for eIF5A1 (as shown in Figure 5C), the low amount of protein used for the $2 \mathrm{D}$ gels only allows the immunodetection of eIF5A1 protein according to the detection limit shown in Figure 5A. The most acidic signal in the western blot coincides with the non-hypusinated proteoform of eIF5A1, whereas the weakest and least acidic signal in the western blot overlaps with the mobility of both eIF5A2 and eIF5A3 hypusinated proteins. In spite of the co-migration of the non-hypusinated eIF5A1 protein with the most acidid spot detected in the western blot, we further tested whether other post-translational modification such as phosphorylation might be also involved in the altered 2D mobility. As it has been shown that eIF5A is a substrate of the protein kinase CK2 in plants (Łebska et al., 2010) we checked whether A. thaliana dominant negative mutants for CK2 activity (Moreno-Romero et al., 2008) would influence the 2D-E mobility of eIF5A. As shown in Figure S2, conditional inactivation of CK2 upon dexamethasone treatment leads to increased amount of the acidic eIF5A1 spot, therefore an increase in the acidic spot cannot be attributed to CK2-dependent phosphorylation activity. Moreover, these data indicate that CK2 may alter the activity of DHS enzyme in vivo in A. thaliana as it has been shown that CK2 interacts with and phosphorylates DHS in HeLa cells (Kang and Chung, 2003). These data indicate that a combination of 2D-E and western blot can be used to assess alterations in the 


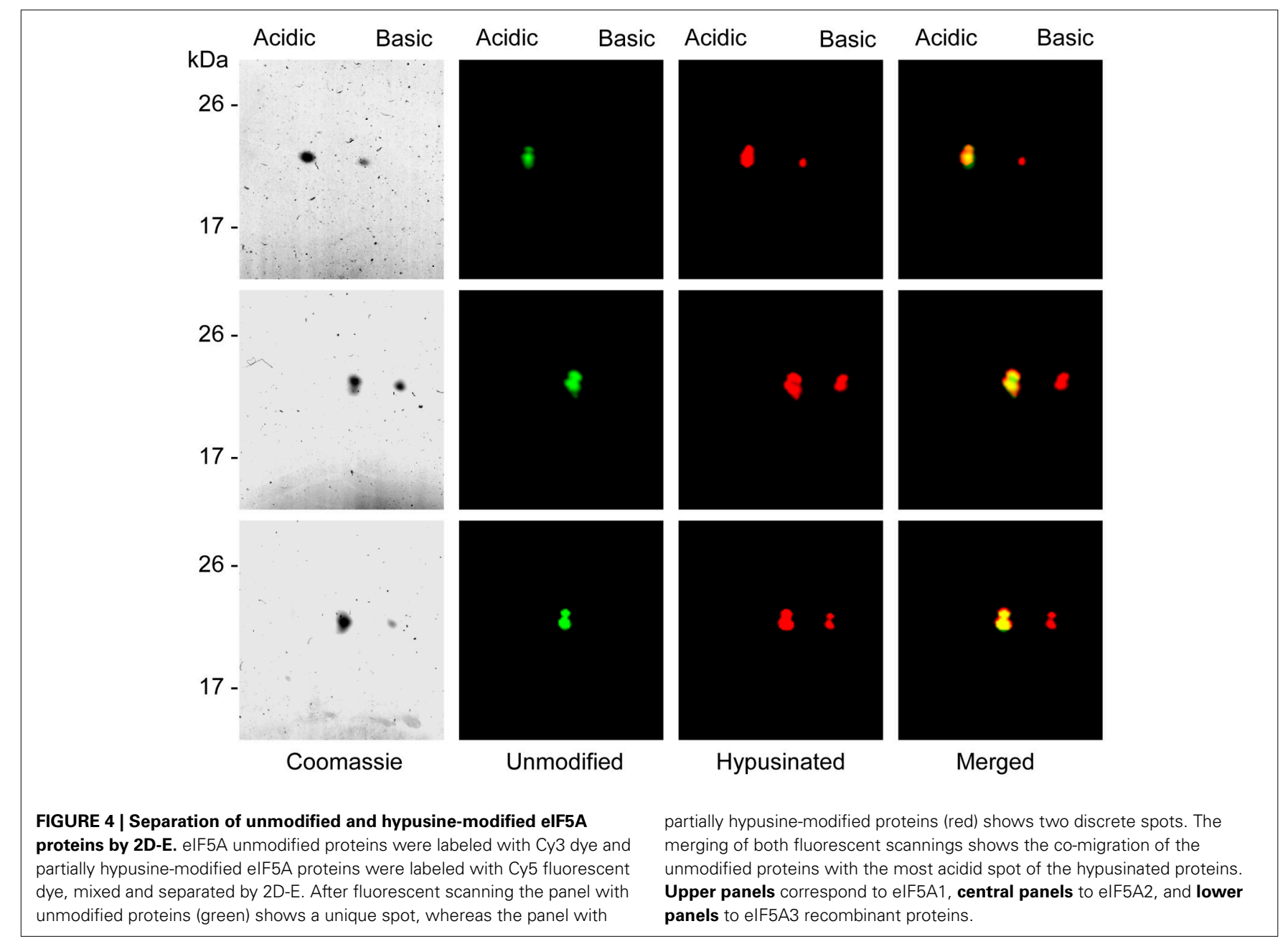

hypusination levels of the A. thaliana eIF5A proteins, in particular for eIF5A1.

\section{ABA REDUCES HYPUSINATION OF EIF5A1 WITHOUT AFFECTING DHS TRANSCRIPT LEVELS}

To validate the use of the proteomic tool aimed to characterize alterations in eIF5A activity, we chose plant treatments with the stress phytohormone abscisic acid (ABA), since it has recently been shown that ABA inhibits global protein translation (Guo et al., 2011). We speculated that such global alteration may also involve the activity of eIF5A. We therefore obtained total protein extracts from seedlings of the same age treated, or not, with ABA. Figure 6A shows a weak acidic spot coincident with the non-hypusinated eIF5A1 protein that increases upon ABA treatment. In the Figure 6A lower panel of the changes detected after 2DE-westernt analysis after ABA treatment were compared with the mobility of the partially hypusinated fluorescent-labeled eIF5A proteins to show a clear overlapping of the ABA-dependent increased acidic spot with the non-hypusinated eIF5A1 protein. Transcriptional analysis did not show any gene expression difference for either eIF5A genes or DHS, although ABA-inducible genes ( $R A B 18$ and $R D 29 B$ ) were clearly induced (Figure 6B). Therefore, post-transcriptional alterations upon ABA increase may alter the activity of eIF5A by reducing its activation by hypusination and this might cause alterations in translation efficiency for the potential beneficiaries of eIF5A activity.

\section{DISCUSSION}

The protein translation factor eIF5A has been recently linked to the translation elongation machinery in addition to the canonical factors eEF1A and eEF2. One key feature of eIF5A relies on its post-translational activation by hypusination, as it is the only protein known that is subject to this modification. Our work aimed at the biochemical characterization of the eIF5A modification pathway in plants. Other eukaryotic systems have already been exhaustively characterized at this level (Xu and Chen, 2001; Lee et al., 2009; Patel et al., 2009; Li et al., 2010; Maier et al., 2010; Dias et al., 2013). In plants, however, much of the efforts have concentrated on genetic approaches for overexpression or antisense, but this type of studies may lead to unwished silencing and moreover a gain-of-function for eIF5A may require simultaneous coexpression of the hypusination enzymes with full activity, which has not been reported yet in plants. Therefore, it seems reasonable to think that any report considering a gain or loss-offunction for the eIF5A hypusination pathway may now include a detailed molecular characterization of its biological activity. 


\section{A}

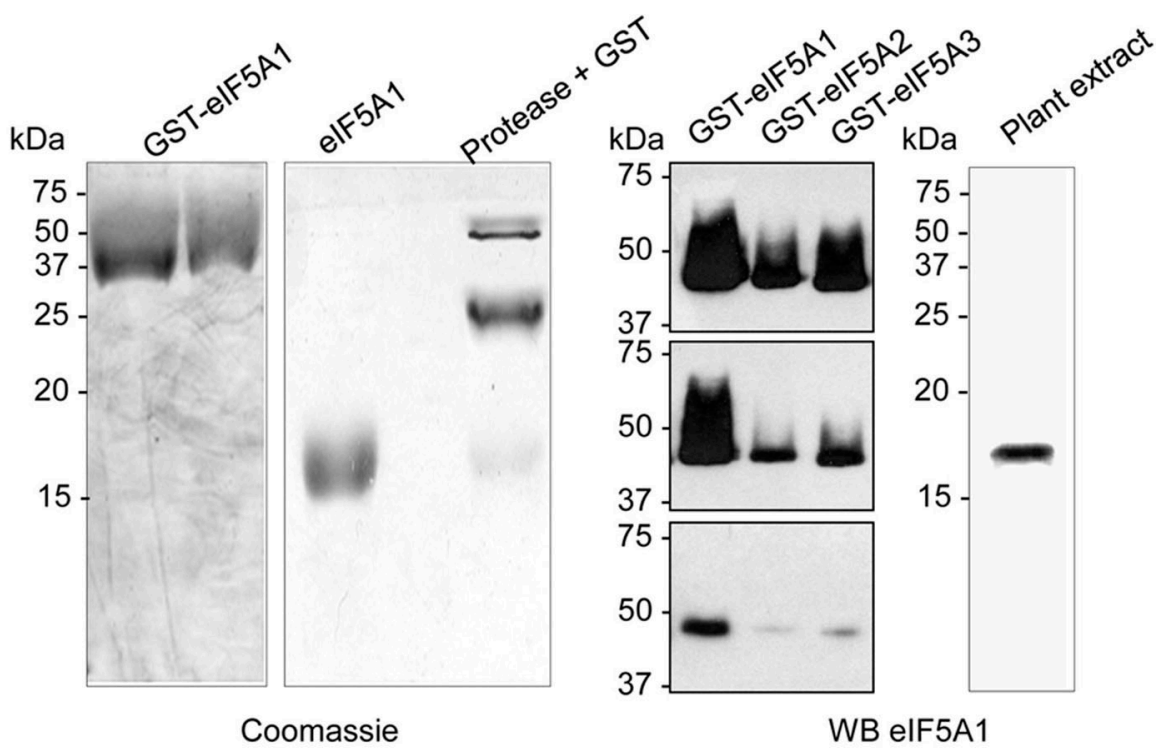

B

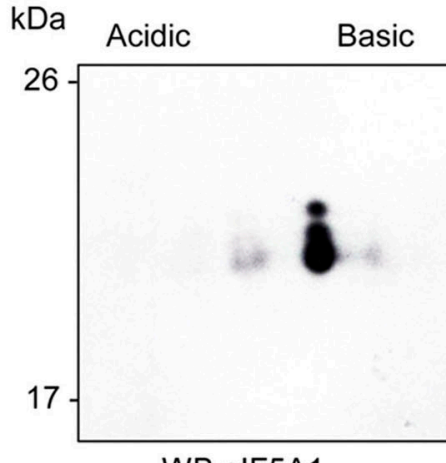

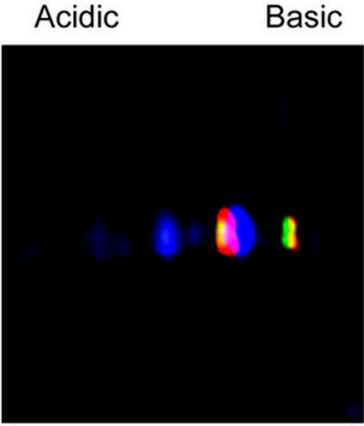

Fluorescence

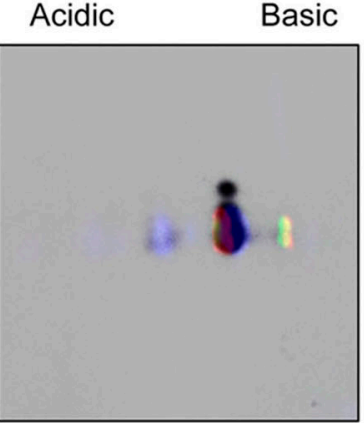

Merged

C

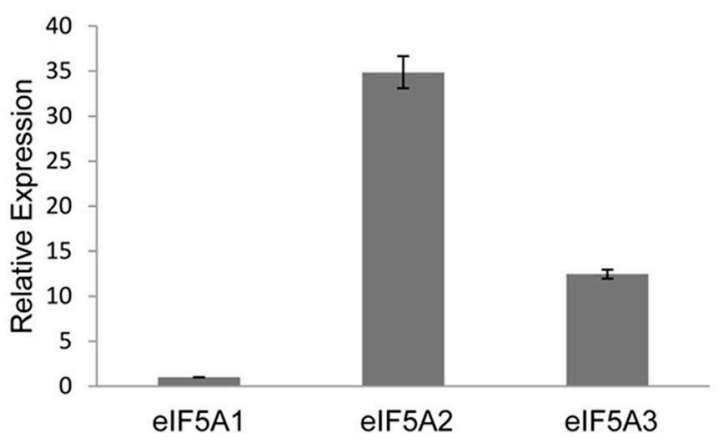

FIGURE 5 | Antibody production and immunological detection of elF5A proteins. Recombinant unmodified GST-elF5A1protein was purified by glutathione sepharose affinity chromatography and cleaved with Protease $3 \mathrm{C}$ to yield highly pure elF5A1 protein (coomassie stained gels on A). The polyclonal antibody generated against elF5A1 protein was used to check cross-reactivity to recombinant GST-elF5A proteins $(1 \mu \mathrm{g}$, $500 \mathrm{ng}$, and $50 \mathrm{ng}$ in the upper, medium, and lower panel, respectively) and immunological detection on total plant protein extract by western blot. Panel (B) shows the comparison of western blot detection of Arabidopsis total protein extract after 2D-E (left) with the fluorescent scanning (middle) of the 2D-E separation of fluorescent labeled recombinant hypusine-modified elF5A proteins (elF5A1 labeled with Cy2, elF5A2 labeled with $\mathrm{Cy} 3$, and elF5A3 labeled with Cy5), and both merged images (right). Panel (C) shows RTqPCR gene expression analysis for elF5A1, elF5A2, and elF5A3 genes relative to elF5A1 gene expression for $A$. thaliana plant seedlings.
Until eIF5A-dependent mRNA targets are found in plants, and appropriate in vivo activity assays are developed, we have focused on the post-translational modification of eIF5A by hypusination that can be monitored by the use of biochemical and immunological techniques. In this work we have developed a $2 \mathrm{D}$-E/western technique to evaluate differences in the relative mobility of each eIF5A protein from A. thaliana. We have successfully expressed recombinant eIF5A proteins as cleavable GST 


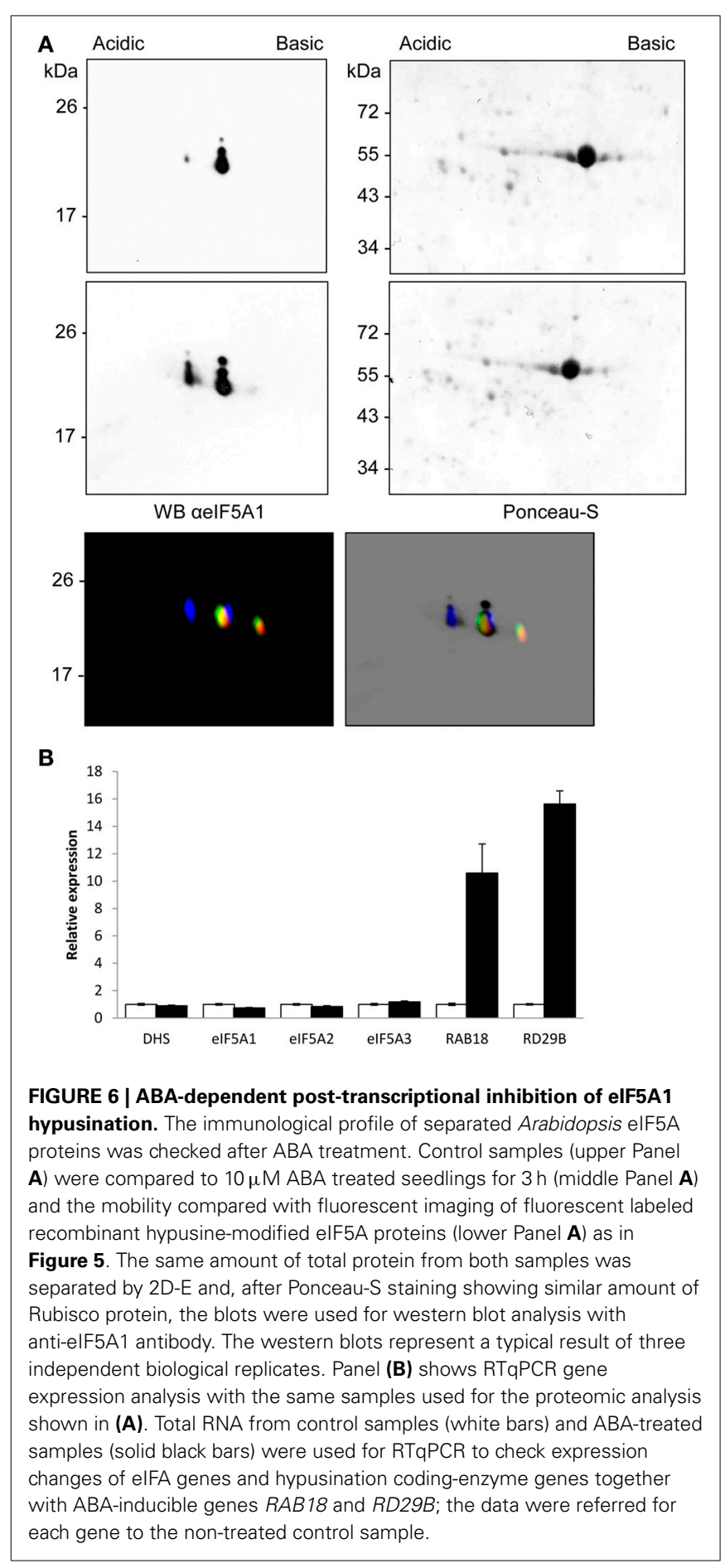

fusion proteins in E. coli both in their unmodified proteoform (Figure 1), and the hypusinated proteoform (Figures 2, 3 and Figure S1). The coexpression of the eIF5A proteins together with the hypusination enzymes facilitated the isolation of soluble proteins demonstrated to be appropriately (if not completely) modified, since the percentage of hypusinated protein was far from complete and displayed variation from one eIF5A protein to another (Figure 4). The fluorescent labeled proteins allowed us to establish a 2D-E map for all three eIF5A proteins in their modified and unmodified proteoforms (Figure 5). When combined with total protein extracts, the immunologically detected eIF5A proteins could be allocated to their hypusine-modified or non-modified proteoforms. As a proof of concept, we have shown that exogenous $\mathrm{ABA}$ treatments may cause inactivation of eIF5A by the increased amount of the non-hypusinated eIF5A1 protein (Figure 6). We have discarded that alterations in the mobility of the acidic spot could be due to other post-translational modifications such as phosphorylation, at least with regard to the well-established activity of the CK2 kinase that has also been shown to occur in plants (Figure S2). Other described posttranslational modification that could lead to increased acidic spot for eIF5A is the acetylation of a close $\mathrm{K}$ to the one modified by hypusination (Ishfaq et al., 2012). Although we cannot formally exclude that such modification is detectable in A. thaliana, at least two additional acidic spots should be present, one highly acidic for the only acetylated proteoform and another, similar in net charge to the non-hypusinated proteoform, corresponding to the doubly modified by acetylation and hypusination in different lysines if this modification system is conserved in plants. Further experiments are required to discriminate whether both modifications are present simultaneously or under different growth conditions in A. thaliana. In the meantime, the biochemical characterization shown with this work can be further applied to other plant treatments or growing conditions, and are also amenable to be used for characterization of transgenic plants with genetic alterations of $e I F 5 A$ genes.

One biological consequence of the detected ABA-dependent alteration in the hypusination of eIF5A1 is that any mRNA whose translation depends on eIF5A may suffer a translational defect under those conditions. According to the recently reported evidences in yeast that eIF5A promotes the translation of polyproline motifs (Gutierrez et al., 2013), it could be envisaged that a similar situation does happen in higher plants. A list of $A$. thaliana proteins containing at least 3 consecutive prolines yields more than 3500 which is a very large number of potential direct eIF5A targets. However, if the assumption is correct, a straightforward strategy to identify ABA-dependent eIF5A targets is to study in detail the translational profile of mRNAs encoding polyproline motifs, a true challenge for future studies in plants.

There are also a number of potential applications of the available hypusinated or non-modified recombinant eIF5A proteins from $A$. thaliana. Future studies with the hypusine-modified or non-modified recombinant eIF5A proteins may include, among others, structural analysis of the ribosome-bound proteins, in vitro translational studies, mRNA-binding tests, and pharmacological screenings of inhibitors of the DHS modification enzyme. As the knowledge of the eIF5A-dependent pathway increases with the identification of mRNA targets, an increase in the demand of both in vitro and in vivo approaches to characterize this pathway is expected to occur. We hope that the biochemical procedures developed and validated with this work will provide a much needed methodology to enable further studies.

\section{ACKNOWLEDGMENTS}

We thank Susana Tárraga from the Proteomics Service at the Instituto de Biología Molecular y Celular de Plantas for her 
excellent technical assistance with the 2D-E and fluorescent labeling. We are indebted to Sergio Ciordia of the Proteomics Unit of the Centro Nacional de Biotecnología (Madrid) and Luz Valero of the SCSIE Proteomics laboratory of the Universidad de Valencia for the help with MS data handling and database submission. We acknowledge funding from the Spanish MICINN/MINECO (BIO2009-11818 and BIO2011-23828). Borja Belda-Palazón is a recipient of a VALi+d predoctoral (ACIF2010/085) contract of the Generalitat Valenciana. The authors gratefully acknowledge Miguel A. Blázquez for critical reading of the manuscript and stimulating discussions.

\section{SUPPLEMENTARY MATERIAL}

The Supplementary Material for this article can be found online at: http://www.frontiersin.org/journal/10.3389/fpls. 2014.00202/abstract

\section{Figure S1 | Determination of the presence of hypusine by GCMS.}

GCxGC/TOF-MS extracted ion chromatogram (m/z $375+174$ ) of

GST-elF5A3 hydrolyzed protein. (A) Hypusinated; (B) non-hypusinated control; (C) mass spectrum of hypusine-TMS.

Figure S2 | CK2-dependent phosphorylation changes in elF5A1 protein. The same amount of protein extract from 10 old day CKA3mut plants grown additionally for 3 days in the absence (A) or in the presence (B) of $10 \mu \mathrm{M}$ dexamethasone, for $\mathrm{CK} 2$ conditional inactivation, were subjected to 2D-E and western blot analysis with anti-elF5A1 antibody. Similar results were obtained in two independent technical replicates.

\section{REFERENCES}

Belda-Palazón, B., Ruiz, L., Martí, E., Tárraga, S., Tiburcio, A. F., Culiáñez, F., et al. (2012). Aminopropyltransferases involved in polyamine biosynthesis localize preferentially in the nucleus of plant cells. PLoS ONE 7:e46907. doi: 10.1371/journal.pone.0046907

Bergeron, R. J., Weimar, W. R., Müller, R., Zimmerman, C. O., McCosar, B. H., Yao, H., et al. (1998). Synthesis of reagents for the construction of hypusine and deoxyhypusine peptides and their application as peptidic antigens. J. Med. Chem. 41, 3888-3900. doi: 10.1021/jm980389p

Chattopadhyay, M. K., Park, M. H., and Tabor, H. (2008). Hypusine modification for growth is the major function of spermidine in Saccharomyces cerevisiae polyamine auxotrophs grown in limiting spermidine. Proc. Natl. Acad. Sci. U.S.A. 105, 6554-6559. doi: 10.1073/pnas.0710970105

Chevallet, M., Luche, S., and Rabilloud, T. (2006). Silver staining of proteins in polyacrylamide gels. Nat. Protoc. 1, 1852-1858. doi: 10.1038/nprot. 2006.288

Cuevas, J. C., Lopez-Cobollo, R., Alcazar, R., Zarza, X., Koncz, C., Altabella, T., et al. (2008). Putrescine is involved in Arabidopsis freezing tolerance and cold acclimation by regulating abscisic acid levels in response to low temperature. Plant Physiol. 148, 1094-1105. doi: 10.1104/pp.108.122945

Czechowski, T., Stitt, M., Altmann, T., Udvardi, M. K., and Scheible, W. R. (2005). Genome-wide identification and testing of superior reference genes for transcript normalization in Arabidopsis. Plant Physiol. 139, 5-17. doi: 10.1104/pp.105.063743

Dias, C., Garcia, W., Zanelli, C., and Valentini, S. (2013). eIF5A dimerizes not only in vitro but also in vivo and its molecular envelope is similar to the EF-P monomer. Amino Acids 44, 631-644. doi: 10.1007/s00726-012-1387-7

Doerfel, L. K., Wohlgemuth, I., Kothe, C., Peske, F., Urlaub, H., and Rodnina, M. V. (2013). EF-P is essential for rapid synthesis of proteins containing consecutive proline residues. Science 339, 85-88. doi: 10.1126/science.1229017

Duguay, J., Jamal, S., Liu, Z., Wang, T. W., and Thompson, J. E. (2007). Leafspecific suppression of deoxyhypusine synthase in Arabidopsis thaliana enhances growth without negative pleiotropic effects. J. Plant. Physiol. 164, 408-420. doi: 10.1016/j.jplph.2006.02.001

Feng, H., Chen, Q., Feng, J., Zhang, J., Yang, X., and Zuo, J. (2007). Functional characterization of the Arabidopsis eukaryotic translation initiation factor
5A-2 that plays a crucial role in plant growth and development by regulating cell division, cell growth, and cell death. Plant Physiol. 144, 1531-1545. doi: 10.1104/pp.107.098079

Gregio, A. P. B., Cano, V. P. S., Avaca, J. S., Valentini, S. R., and Zanelli, C. F. (2009). eIF5A has a function in the elongation step of translation in yeast. Biochem. Biophys. Res. Commun. 380, 785-790. doi: 10.1016/j.bbrc.2009.01.148

Guo, J., Wang, S., Valerius, O., Hall, H., Zeng, Q., Li, J.-F., et al. (2011). Involvement of Arabidopsis RACK1 in protein translation and its regulation by abscisic acid. Plant Physiol. 155, 370-383. doi: 10.1104/pp.110.160663

Gutierrez, E., Shin, B.-S., Woolstenhulme, C. J., Kim, J.-R., Saini, P., Buskirk, A. R., et al. (2013). eIF5A promotes translation of polyproline motifs. Mol. Cell 51, 35-45. doi: 10.1016/j.molcel.2013.04.021

Hamasaki-Katagiri, N., Tabor, C. W., and Tabor, H. (1997). Spermidine biosynthesis in Saccharomyces cerevisiae: polyamine requirement of a null mutant of the SPE3 gene (spermidine synthase). Gene 187, 35-43. doi: 10.1016/S0378$1119(96) 00660-9$

Imai, A., Matsuyama, T., Hanzawa, Y., Akiyama, T., Tamaoki, M., Saji, H., et al. and Takahashi, T. (2004). Spermidine synthase genes are essential for survival of Arabidopsis. Plant Physiol. 135, 1565-1573. doi: 10.1104/pp.104.041699

Ishfaq, M., Maeta, K., Maeda, S., Natsume, T., Ito, A., and Yoshida, M. (2012). Acetylation regulates subcellular localization of eukaryotic translation initiation factor 5A (eIF5A). FEBS Lett. 586, 3236-3241. doi: 10.1016/j.febslet.2012.06.042

Jin, B. F., He, K., Wang, H. X., Wang, J., Zhou, T., Lan, Y., et al. (2003). Proteomic analysis of ubiquitin-proteasome effects: insight into the function of eukaryotic initiation factor 5A. Oncogene 22, 4819-4830. doi: 10.1038/sj.onc.1206738

Kang, H. A., and Hershey, J. W. B. (1994). Effect of initiation-factor eIF5A depletion on protein-synthesis and proliferation of Saccharomyces cerevisiae. J. Biol. Chem. $269,3934-3940$.

Kang, K. R., and Chung, S. I. (2003). Protein kinase CK2 phosphorylates and interacts with deoxyhypusine synthase in HeLa cells. Exp. Mol. Med. 35, 556-564. doi: $10.1038 / \mathrm{emm} .2003 .73$

Klier, H., Csonga, R., Joao, H. C., Eckerskorn, C., Auer, M., Lottspeich, F., and Eder, J. (1995). Isolation and structural characterization of different isoforms of the hypusine-containing protein eIF-5A from HeLa cells. Biochemistry 34, 14693-14702. doi: 10.1021/bi00045a010

Łebska, M., Ciesielski, A., Szymona, L., Godecka, L., Lewandowska-Gnatowska, E., Szczegielniak, J., and Muszyñska, G. (2010). Phosphorylation of Maize Eukaryotic Translation Initiation Factor 5A (eIF5A) by Casein Kinase 2. J. Biol. Chem. 285, 6217-6226. doi: 10.1074/jbc.M109.018770

Lee, S. B., Park, J. H., Kaevel, J., Sramkova, M., Weigert, R., and Park, M. H. (2009). The effect of hypusine modification on the intracellular localization of eIF5A. Biochem. Biophys. Res. Commun. 383, 497-502. doi: 10.1016/j.bbrc.2009.04.049

Li, C. H., Ohn, T., Ivanov, P., Tisdale, S., and Anderson, P. (2010). eIF5A promotes translation elongation, polysome disassembly and stress granule assembly. PLoS ONE 5:e9942. doi: 10.1371/journal.pone.0009942

Liu, Z., Duguay, J., Ma, F., Wang, T. W., Tshin, R., Hopkins, M. T., et al. (2008). Modulation of eIF5A1 expression alters xylem abundance in Arabidopsis thaliana. J. Exp. Bot. 59, 939-950. doi: 10.1093/jxb/ern017

Ma, F., Liu, Z., Wang, T. W., Hopkins, M. T., Peterson, C. A., and Thompson, J. E. (2010). Arabidopsis eIF5A3 influences growth and the response to osmotic and nutrient stress. Plant Cell Environ. 33, 1682-1696. doi: 10.1111/j.13653040.2010.02173.x

Maier, B., Ogihara, T., Trace, A. P., Tersey, S. A., Robbins, R. D., Chakrabarti, S. K., et al. (2010). The unique hypusine modification of eIF5A promotes islet $\beta$ cell inflammation and dysfunction in mice. J. Clin. Invest. 120, 2156-2170. doi: 10.1172/JCI38924

Mandal, S., Mandal, A., Johansson, H. E., Orjalo, A. V., and Park, M. H. (2013). Depletion of cellular polyamines, spermidine and spermine, causes a total arrest in translation and growth in mammalian cells. Proc. Natl. Acad. Sci. U.S.A. 110, 2169-2174. doi: 10.1073/pnas.1219002110

Moreno-Romero, J., Carme Espunya, M., Platara, M., Ariño, J., and Carmen Martínez, M. (2008). A role for protein kinase CK2 in plant development: evidence obtained using a dominant-negative mutant. Plant J. 55, 118-130. doi: 10.1111/j.1365-313X.2008.03494.x

Nishimura, K., Lee, S., Park, J., and Park, M. (2012). Essential role of eIF5A-1 and deoxyhypusine synthase in mouse embryonic development. Amino Acids 42, 703-710. doi: 10.1007/s00726-011-0986-z

Nishimura, K. F., Ohki, Y. F., Fukuchi-Shimogori, T. F., Sakata, K. F., Saiga, K. F., Beppu, T. F., et al. (2002). Inhibition of cell growth through inactivation of 
eukaryotic translation initiation factor 5A (eIF5A) by deoxyspergualin. Biochem J. 363, 761-768. doi: 10.1042/0264-6021:3630761

Pagnussat, G. C., Yu, H. J., Ngo, Q. A., Rajani, S., Mayalagu, S., Johnson, C. S., et al. (2005). Genetic and molecular identification of genes required for female gametophyte development and function in Arabidopsis. Development 132, 603-614. doi: 10.1242/dev.01595

Park, J. H., Dias, C. A. O., Lee, S. B., Valentini, S. R., Sokabe, M., Fraser, C. S., et al. (2011). Production of active recombinant eIF5A: reconstitution in E. coli of eukaryotic hypusine modification of eIF5A by its coexpression with modifying enzymes. Protein Eng. Des. Select. 24, 301-309. doi: 10.1093/protein/gzq110

Park, M. (2006). The post-translational synthesis of a polyamine-derived amino acid, hypusine, in the eukaryotic translation initiation factor 5A (eIF5A) J. Biochem. 139, 161-169. doi: 10.1093/jb/mvj034

Park, M. H., Lee, Y. B., and Joe, Y. A. (1997). Hypusine is essential for eukaryotic cell proliferation. Biol. Signals 6, 115-123. doi: 10.1159/000109117

Park, M. H., Wolff, E. C., and Folk, J. E. (1993). Hypusine - its posttranslational formation in eukaryotic initiation factor-5A and its potential role in cellularregulation. Biofactors 4, 95-104.

Patel, P. H., Costa-Mattioli, M., Schulze, K. L., and Bellen, H. J. (2009). The Drosophila deoxyhypusine hydroxylase homologue nero and its target eIF5A are required for cell growth and the regulation of autophagy. J. Cell Biol. 185, 1181-1194. doi: 10.1083/jcb.200904161

Ren, B., Chen, Q., Hong, S., Zhao, W., Feng, J., Feng, H., et al. (2013). The Arabidopsis eukaryotic translation initiation factor eIF5A-2 regulates root protoxylem development by modulating cytokinin signaling. Plant Cell 25, 3841-3857. doi: 10.1105/tpc.113.116236

Saez, A., Robert, N., Maktabi, M. H., Schroeder, J. I., Serrano, R., and Rodriguez, P. L. (2006). Enhancement of abscisic acid sensitivity and reduction of water consumption in Arabidopsis by combined inactivation of the protein phosphatases type 2C ABI1 and HAB1. Plant Physiol. 141, 1389-1399. doi: 10.1104/pp.106.081018

Saini, P., Eyler, D. E., Green, R., and Dever, T. E. (2009). Hypusine-containing protein eIF5A promotes translation elongation. Nature 459, 118-121. doi: 10.1038 /nature 08034

Scheich, C., Kümmel, D., Soumailakakis, D., Heinemann, U., and Büssow, K. (2007). Vectors for co-expression of an unrestricted number of proteins. Nucleic Acids Res. 35, e43. doi: 10.1093/nar/gkm067

Shevchenko, A., Jensen, O. N., Podtelejnikov, A. V., Sagliocco, F., Wilm, M., Vorm, O., et al. (1996). Linking genome and proteome by mass spectrometry: largescale identification of yeast proteins from two dimensional gels. Proc. Natl. Acad. Sci. U.S.A. 93, 14440-14445. doi: 10.1073/pnas.93.25.14440

Strohalm, M., Hassman, M., Košata, B., and Kodíček, M. (2008). mMass data miner: an open source alternative for mass spectrometric data analysis. Rapid Commun. Mass Spectrom. 22, 905-908. doi: 10.1002/rcm.3444
Vizcaíno, J. A., Côté, R. G., Csordas, A., Dianes, J. A., Fabregat, A., Foster, J. M., et al. (2013). The Proteomics Identifications (PRIDE) database and associated tools: status in 2013. Nucleic Acids Res. 41, D1063-D1069. doi: 10.1093/nar/gks1262

Wang, L., Xu, C., Wang, C., and Wang, Y. (2012). Characterization of a eukaryotic translation initiation factor $5 \mathrm{~A}$ homolog from Tamarix androssowii involved in plant abiotic stress tolerance. BMC Plant Biol. 12:118. doi: 10.1186/1471-222912-118

Wolff, E. C., Kang, K. R., Kim, Y. S., and Park, M. H. (2007). Posttranslational synthesis of hypusine: evolutionary progression and specificity of the hypusine modification. Amino Acids 33, 341-350. doi: 10.1007/s00726-007-0525-0

$\mathrm{Xu}, \mathrm{A}$., and Chen, K. Y. (2001). Hypusine is required for a sequence-specific interaction of eukaryotic initiation factor $5 \mathrm{~A}$ with postsystematic evolution of ligands by exponential enrichment RNA. J. Biol. Chem. 276, 2555-2561. doi: 10.1074/jbc.M008982200

Xu, A., Jao, D. L.-E., and Chen, K. Y. (2004). Identification of mRNA that binds to eukaryotic initiation factor $5 \mathrm{~A}$ by affinity co-purification and differential display. Biochem. J. 384, 585-590. doi: 10.1042/BJ20041232

Xu, J., Zhang, B., Jiang, C., and Ming, F. (2011). RceIF5A, encoding an eukaryotic translation initiation factor $5 \mathrm{~A}$ in Rosa chinensis, can enhance thermotolerance, oxidative and osmotic stress resistance of Arabidopsis thaliana. Plant Mol. Biol. 75, 167-178. doi: 10.1007/s11103-010-9716-2

Zanor, M. I., Rambla, J.-L., Chaïb, J., Steppa, A., Medina, A., Granell, A., et al. (2009). Metabolic characterization of loci affecting sensory attributes in tomato allows an assessment of the influence of the levels of primary metabolites and volatile organic contents. J. Exp. Bot. 60, 2139-2154. doi: 10.1093/jxb/erp086

Conflict of Interest Statement: The authors declare that the research was conducted in the absence of any commercial or financial relationships that could be construed as a potential conflict of interest.

Received: 28 February 2014; accepted: 24 April 2014; published online: 16 May 2014. Citation: Belda-Palazón B, Nohales MA, Rambla JL, Aceña JL, Delgado O, Fustero S, Martinez MC, Granell A, Carbonell J and Ferrando A (2014) Biochemical quantitation of the eIF5A hypusination in Arabidopsis thaliana uncovers ABA-dependent regulation. Front. Plant Sci. 5:202. doi: 10.3389/fpls.2014.00202

This article was submitted to Plant Proteomics, a section of the journal Frontiers in Plant Science.

Copyright (C) 2014 Belda-Palazón, Nohales, Rambla, Aceña, Delgado, Fustero, Martínez, Granell, Carbonell and Ferrando. This is an open-access article distributed under the terms of the Creative Commons Attribution License (CC BY). The use, distribution or reproduction in other forums is permitted, provided the original author(s) or licensor are credited and that the original publication in this journal is cited, in accordance with accepted academic practice. No use, distribution or reproduction is permitted which does not comply with these terms. 